\title{
Improving Mental Wellbeing of Undergraduate Students During COVID-19 Pandemic
}

\author{
Ratna Sari $^{1^{*}}$ M Nurul Ikhsan Saleh ${ }^{2}$

 \\ ${ }^{2}$ Faculty of Islamic Studies, Universitas Islam Indonesia, Indonesia. \\ *Email: ratna.sari@umy.ac.id
}

\begin{abstract}
The research investigated the emotions and evaluated the effectiveness of undergraduate students on Expressive Writing during the online learning process in the pandemic of COVID-19. The subjects are 122 undergraduate students divided into experiment and control groups. The quasi-experimental and thematic analysis method was used to analyze the data. The data were collected by conducting pretest, observation, and posttest. Warwick-Edinburgh Mental Wellbeing Scale (WEMWBS) was used on pretest and posttest to measure the undergraduate students' mental wellbeing. WEMWBS is a 14-item scale covering subjective wellbeing and psychological functioning. The research reveals three major findings. Firstly, inboth the control and experimental groups, females experienced positive changes in wellbeing scores, while males did not experience positive changes. Secondly, the mean score of mental wellbeing in the control group slightly increases, which is not significant. Thirdly, it also finds no significant difference between pretest and posttest scores in both experiment and control groups. In other words, Expressive Writing could not improve undergraduate students' mental wellbeing. This study's results are valuable for educators, students, and education practitioners to develop mental wellbeing treatment.
\end{abstract}

Keywords: Mental Wellbeing, Expressive Writing, Emotion

\section{INTRODUCTION}

The novel coronavirus disease 2019 (COVID-19) first appeared in Wuhan, China's capital, Hubei Province, in December 2019 [1]. The World Health Organization (WHO) declared COVID-19 as a pandemic in March 2020 [2]. The virus has spread to more than 154 countries worldwide and infected more than 150,000 people on March 14, 2020 [3]. In Indonesia, the spread of COVID-19 has a significant effect on the economy and the education sector [4]. The Indonesian government set several regulations due to increased COVID-19 cases, namely, work from home, worship at home, and school from home for students at all education levels, including college [5]. Universities worldwide also postpone or cancel all campus activities, such as workshops, conferences, seminars, and other face-to-face activities [6]. University lectures are rapidly changing from face-to-face lectures to online lectures using various online learning platforms such as Moodle, Google classroom, Zoom, Microsoft Teams, and other online media.

On the one hand, using online learning provides positive sides during the Covid-19 pandemic Covid-19, but on the other hand, the online learning system in some research also creates problems for students, such as academic stress arising from the significant online assignments [7]. Students also need to adapt to study independently and accomplish assignments in a disciplined manner according to the deadlines set by each lecturer who teaches the course. The cases of academic stress are part of mental distress that allows academic failure [8]. Furthermore, the learning process in the Covid-19 pandemic also has a profound effect on individuals' mental health and well-being [9]. In other studies, the Covid-19 pandemic has influenced undergraduate medical students on their confidence to become doctors [10], the impact on 
student learning gaps [11], and the psychological impact such as stress [12].

Based on the previous studies regarding the impact of the Covid-19 Pandemic on the Wellbeing of undergraduate students, the researcher concluded that further research is needed regarding how to improve the Mental well-being of undergraduate students during the Covid-19 Pandemic. This study used a Quasi-Experimental Design to specifically examine the Mental Wellbeing of undergraduate students during the Covid-19 Pandemic. This research is valuable not only for the development of research in the field of Mental Well-being during the Pandemic but also this research is expected to provide some feedback to policymakers and stakeholders in the education and health sectors.

\section{LITERATURE REVIEW}

\subsection{Mental Well-being}

The term of mental well-being is often confused with the term positive mental health. Recently, the study of well-being has become a material that is increasingly being carried out in research. There have been attempts by researchers to find the right concept for mental well-being. One of the efforts done by researchers is to create a scale to measure mental wellbeing. The Warwick-Edinburgh Mental Well-Being Scale (WEMWBS) is a scale used to capture the concept of well-being, which consists of dimensions of psychological function and dimensions of well-being and emotional [13]. In the current Covid-19 pandemic, this mental well-being approach is very relevant to be used, especially for monitoring psychological wellbeing [14], where the case of the spread of the Covid-19 pandemic itself has caused millions of cases or deaths in many countries in the world.

Mental wellbeing is a positive state of psychological and emotional health shown by individuals who are cognitively and emotionally running productive and satisfactory [15]. During the COVID-19 outbreak, there has been an increase in psychological problems, such as; high anxiety, depression, and low mental wellbeing [16]. There is a significant relationship between adolescents' depression and educational level [17].

Extreme life stressors such as the COVID-19 pandemic can cause negative emotions and harm an individual's mental wellbeing [18]. Academic studies have a negative impact on students' mental wellbeing [15]. Changing the face-to-face lecture system into an online learning system is one of the stressors experienced by students.

\subsection{Expressive Writing}

Writing is one of the creative writing therapy method invented by James Pennebaker [19]. In expressive writing, the participant involved in the research process is asked to make a story of personal experiences with an estimated time of about half an hour each day. Based on Pennebaker's research, in randomized controlled trials, expressive writing interventions can positively affect an individual's physical and mental health. In a study conducted by Pennebaker, it was shown that there was an improvement in participants in terms of social relationships and an improved immune system [19]. Another study conducted by Staricoff also found that the use of writing in mental health can be used to express thoughts and feelings that function as therapy [20]

In another study, it was revealed that expressive writing is believed to be used in mental health services like counseling and psychotherapy to deal with mental health problems. Expressive writing can increase creativity, strengthen oneself, express oneself, and identify experiences and views. Mcardle considers that expressive writing is believed to overcome mental health problems with specific symptoms by improving well-being. However, Mcardle himself criticized some of these findings, where there is no evidence of clinical effectiveness as evidence [21]. Further research is still needed to obtain evidence of the clinical effectiveness of expressive writing in dealing with specific mental health symptoms. Research in the past few years revealed contradictory findings. The more a person with mental health problems wrote, the more stressed and depressed they would be, especially when writing traumatic events in his lifetime [22].

\subsection{Emotion}

Emotion is the range and quality of individual human experience in everyday life [23]. In more detail, emotions include surprise, sadness, joy, fear, disgust, and anger [24]. In everyday life, someone needs to have the ability to deal with emotional life, which will affect a person's emotional reactions, especially in achieving good health in physical or psychological health. The decrease and increase in negative and positive emotions affect a person's subjective reactions [25].

Several studies examined negative and positive emotions saw the difference between the two. Meanwhile, some researchers make welfare measures as a measure to assess psychological development and that feelings. One of them makes a measure of psychological well-being by making a scale on optimism, life goals, self-esteem, and relationships with others [26]. In another study, research 
was designed to measure a person's emotional response, either positive or negative, in duration, intensity, and activation by making a PERS scale (The Perth Emotional Reactivity Scale). The PERS is believed to have good psychometric properties and is useful in clinical settings [27].

\section{METHODS OF RESEARCH}

\subsection{Participants and Procedure}

The questionnaire was filled out online via the google form platform to collect research data. The google form link is distributed through the Moodle platform to 122 students from a private Islamic university in Yogyakarta, Indonesia. All respondents were undergoing online learning during the COVID-19 pandemic in the period April-May 2020. Respondents were divided into control and experimental groups. In the control class, there were 52 students, 22 boys (42\%), and 30 girls $(58 \%)$ who volunteered to fill out the Mental Wellbeing scale. The Mental Wellbeing scale in the control class is given two times, at pre-intervention and post-intervention. The respondents completed the second scale after a minimum of two weeks from the first scale filling. In the experimental group, there were 70 students, 25 males (36\%), and 45 females (64\%). Respondents volunteered to fill out the scale. Before filling out the second scale, students were given intervention in writing daily stories using the expressive writing method.

\subsection{Intervention}

The intervention given to the experimental class is the expressive writing method. The intervention was carried out after the respondent filled out the first WEMWBS. The intervention lasted three weeks. In the first week, respondents were asked for three days to write down their feelings or experiences on their past or present life journey or their plans and dreams for the future. In the second week of intervention, respondents wrote a daily story containing feelings of sadness, pleasure, or gratitude for four days successively. In the third week, respondents reflect on what feelings or experiences they get after doing expressive writing.

\subsection{Measures}

In this study, mental well-being was measured using the Indonesian version of the Warwick Edinburgh Mental Wellbeing Scale (WEMWBS). This scale consists of 14 items to measure mental health's positive aspects, including subjective well-being and psychological functioning [16]. On this scale, respondents were asked to respond to 14 statements based on what they felt and thought during the last two weeks. Responses consist of five points, ranging from "none of the time" to "all of the time." Respondents need to measure their experience in the past two weeks by selecting one of five response options ranging from 1 for the "none of the time" response to 5 points for the "all of the time" response. Bartram et al. state that this scale has been used in non-western populations such as Chinese and Pakistani people and has excellent internal consistency for both cultural groups of $\alpha>.90[28]$.

\subsection{Research Design}

This study used a quasi-experimental method with a non-equivalent control group design model.

\subsection{Objectives}

The research objective consists of three main points. First, this study aims to determine whether there is a difference in the WEMWBS scores on the pretest and posttest students in both the control class and the experimental class based on gender. Second, this study wants to reveal the mean and proportion of mental wellbeing in the control class and the experimental class. The third research objective is to determine whether expressive writing was effective in improving students' mental wellbeing. Fourth, the purpose of this study is to reveal the emotional patterns of students in expressive writing.

\subsection{Data Analysis}

Mental wellbeing data were analyzed through the WEMWBS Spreadsheet. WEMWBS This spreadsheet has been designed to analyze the Warwick Edinburgh Mental Wellbeing Scale (WEMWBS). Meanwhile, content analysis is used to determine emotional patterns in the results of expressive writing.

\section{RESULTS}

\subsection{Mental Wellbeing}

The mental wellbeing scores in the control and experimental groups based on gender are shown in the Table 1. In both the control and experimental groups, females experienced positive changes in wellbeing scores, while males did not experience positive changes. Male students had high mental wellbeing scores at the pretest and had negative changes in the posttest. In both groups, male students' mental wellbeing scores decreased.

The mean score of mental wellbeing in the control group slightly increases from 52,7 to 52,8 (Table 2). The mean score of mental wellbeing scores in the experimental group slightly rises from 53,1 to 53,3 (Table 3). The proportion of mental wellbeing scores of pre and post- 
intervention in the control group is described in the Table 4. The chart (Table 4) shows that students with low mental wellbeing have increased from $2 \%$ to $8 \%$. Meanwhile, the percentage of students with moderate mental wellbeing scores decreased from $85 \%$ at pretest to $79 \%$ at posttest. As for students with high mental wellbeing scores, the percentage remains the same at pretest and posttest, $13 \%$.

In the experimental group, the proportion of students' mental wellbeing is shown in the Table 5. Students with low mental wellbeing scores are $4 \%$ at pre-intervention and increased to $9 \%$ at post-intervention in the experimental group. Meanwhile, students with moderate mental wellbeing experienced negative changes, with $86 \%$ at pre-intervention decreased to $77 \%$ at post-intervention.
However, there was a positive increase in students with high mental health, an increase of $4 \%$ after the intervention.

The result of the paired sample t-test in the control group is t-count 0.046 and t-table 2.00758; thus, t-count $<$ $\mathrm{t}$-table. Therefore, there is no significant difference in mental health score average in the pretest and posttest. Besides, in the experimental group, the t-count is 0.294 , and the $\mathrm{t}$-table is 1.99547 , so the $\mathrm{t}$-count $<\mathrm{t}$-table. There was no significant difference between mental wellbeing scores at pre-intervention and post-intervention in the experimental group. Thus, expressive writing does not significantly affect students' mental wellbein.

Table 1. Mental wellbeing scores based on gender

\begin{tabular}{ll|l|l|l|l|l|l|l|}
\multicolumn{4}{c}{} & \multicolumn{1}{c}{ Before Intervention } & \multicolumn{3}{c}{ After Intervention } & \multicolumn{3}{c}{ Change } & \multicolumn{4}{c}{ Positive Change } \\
\cline { 2 - 9 } & Male & Female & Male & Female & Male & Female & Male & Female \\
\hline Control Group & 54.7 & 51.2 & 51.8 & 53.5 & -2.95 & 2.27 & No & Yes \\
\hline Experiment Group & 53.5 & 52.9 & 52.5 & 53.7 & -1.00 & 0.80 & No & Yes \\
\cline { 2 - 10 }
\end{tabular}

Table 2. Mean score in the control group



Table 4. The proportion of the control group

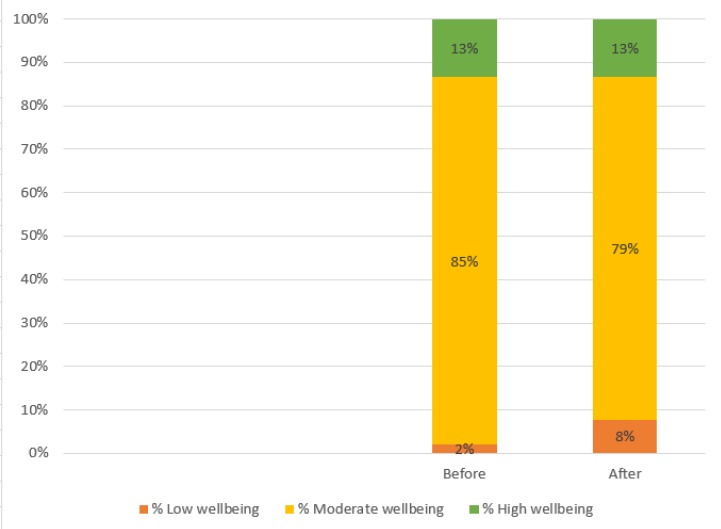

Table 3. Mean score in the experiment group

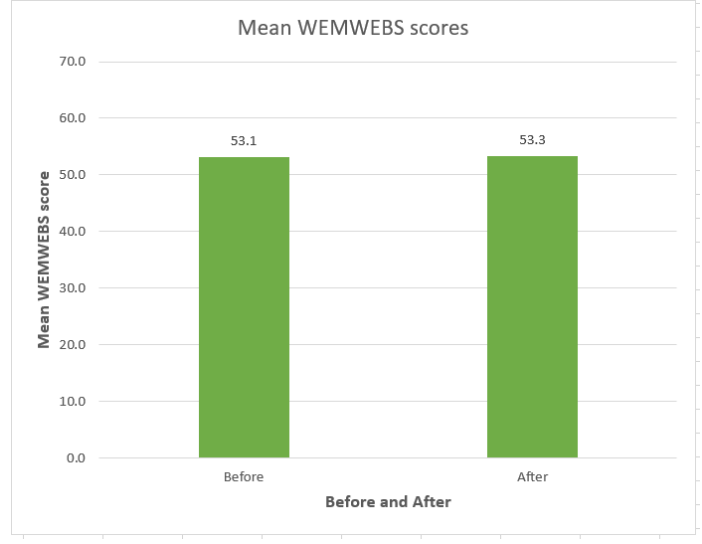

Table 5. The proportion of experiment group

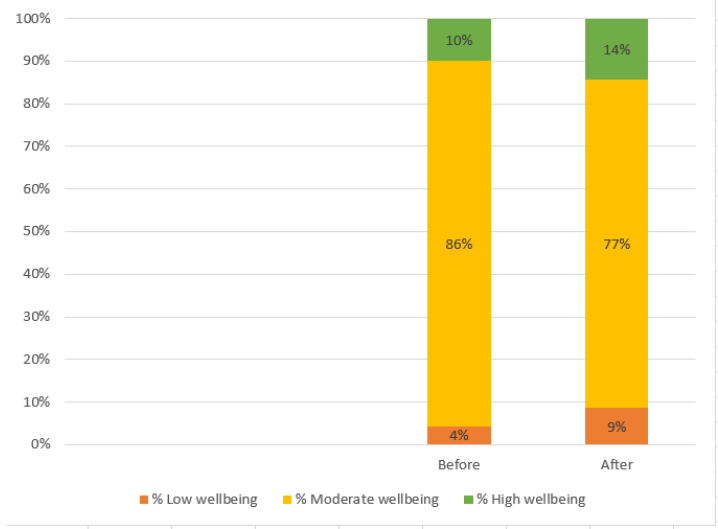




\subsection{Expressive writing}

Table 6. Expressive Writing Emotion



The results of emotional mapping from expressive writing interventions are as seen above. In the first week of implementing expressive writing intervention (1.11.3 ), it can be seen that joy and sadness dominate among other types of emotions. Forty-one respondents (59\%) raised positive emotions in the form of joy in their writing at the last intervention in the first week. In the second week of intervention (2.1-2.4), three types of emotions dominate: joy, sadness, and gratitude. In the third week (3.1), positive emotions in the form of joy were seen to be the highest compared to other types of emotions.

\section{DISCUSSION}

The COVID-19 pandemic is happening, and it had become a global crisis when this research was conducted. This pandemic has a profound effect on the mental wellbeing of both males and females. Mental wellbeing is influenced by direct and indirect trauma and perceptions of risk [14]. Gender norms on emotional expression have different effects on males and females [29]. In this study, it was found that female students' mental wellbeing tended to change positively after the intervention, while male students' mental wellbeing had negative changes. This study indicates that female students can express their feelings through expressive writing than male students. Female students wrote longer and displayed a greater variety of emotions during the intervention. Male students tend to display more limited emotional experiences and expressions than females [30]. It can happen because males are generally not encouraged to express negative emotions such as sadness and anxiety, which indicate dependence and weakness [31]. The female's score is significantly higher than the male's score in the self-report measure [32]. Through expressive writing intervention, female students get more psychological improvement than male students [33].
The results of several studies indicate that the WEMWBS scale can detect positive changes in the mental wellbeing of respondents from pre-intervention to post-intervention [34]. The results of this study show positive changes in the mean of the control class and experimental class. Both groups experienced an increase in the average of students' mental wellbeing score, although it was minimal, specifically 0.1 in the control group and 0.2 in the experimental group.

Based on the proportion of mental wellbeing scores in the control and the experimental group, it can be seen that there is a similar trend. The trend is that the percentage of students with moderate mental wellbeing is high at pre-intervention and decreased postintervention. In contrast, the percentage of students with low mental wellbeing is low at preintervention and increased in post-intervention. Thus, both the control and the experimental group experienced the same trend, which is a decrease in mental wellbeing scores at postintervention. Several vital points cause this trend, such as students' adaptation, uncertainty, inadequate computers and IT equipment, and overload assignments.

All academicians need to have a high readiness rate to adapt to changes in the lecture system during the COVID-19 pandemic [35]. Unpreparedness or difficulty in adapting is a stressor that can affect mental health. Besides, the COVID-19 pandemic globally changes all citizens' routines, including campuses and students' lives. One of the fears affected by COVID-19 is uncertainty [14]. Therefore, uncertainty in the current situation can be considered a significant risk factor affecting psychological well-being [14]. Computers and IT equipment are currently the primary needs of students undergoing online learning [6]. However, not all students have access to computers and inadequate internet access. These two things are the biggest obstacles to the implementation of online learning in Indonesia [36]. The overload of online assignments that 
students have to do is a stressor that can impact mental health. Stress will also affect student academic performance [7].

The results of this study found that expressive writing intervention did not significantly influence students' mental wellbeing. It can happen because of the influence of several things that have been discussed above, such as gender, student adaptation level, uncertainty, inadequate computers and IT equipment, and overload assignments. Other factors may influence mental wellbeing, so further research is needed to explore mental wellbeing during the Covid-19 pandemic.

In emotion mapping, expressive writing results found three dominant emotions: joy, thankfulness, and sadness. Joy and thankfulness are classified as positive emotions, while sadness is a negative emotion. However, the average number of students who showed positive emotions were higher than those who showed negative emotions, such as sadness. Gratitude activities lead individuals to recall memories that are very meaningful and are one of the ways that can improve wellbeing [37]. Furthermore, grateful people generally have healthier, mentally and physically [38]. Furthermore, joy, which is a positive emotion, significantly affects an individual's mental wellbeing. Conversely, dysfunctional regulation of positive emotion results in poor mental health outcomes [39].

\section{CONCLUSION}

In summary, this study demonstrates three major findings. Firstly, in both the control and experimental groups, females experienced positive changes in wellbeing scores, while males did not experience positive changes. Secondly, the mean score of mental wellbeing in the control group slightly increases from 52,7 to 52,8 and the mean score of mental wellbeing scores in the experimental group slightly rise from 53,1 to 53,3 . Thirdly, expressive writing intervention is ineffective in improving mental wellbeing. Further exploration is needed, mainly to find out the proper mental wellbeing interventions for students.

\section{REFERENCES}

[1] M. Chahrour et al., "A Bibliometric Analysis of COVID-19 Research Activity: A Call for Increased Output," Cureus, vol. 2, no. December 2019, pp. 1-8, 2020, doi: 10.7759/cureus. 7357.

[2] C. Sohrabi et al., "World Health Organization declares global emergency: A review of the 2019 novel coronavirus (COVID-19)," Int. J. Surg., vol. 76, no. February, pp. 71-76, 2020, doi: 10.1016/j.ijsu.2020.02.034.

[3] H. H. Khachfe, M. Chahrour, J. Sammouri, H. A. Salhab, B. E. Makki, and M. Y. Fares, "An Epidemiological Study on COVID-19: A Rapidly Spreading Disease," Cureus, vol. 12, no. 3, 2020, doi: 10.7759/cureus.7313.

[4] A. Abidah, H. N. Hidaayatullaah, R. M. Simamora, D. Fehabutar, and L. Mutakinati, "The Impact of Covid-19 to Indonesian Education and Its Relation to the Philosophy of 'Merdeka Belajar,'" Stud. Philos. Sci. Educ., vol. 1, no. 1, pp. 38-49, 2020, doi: 10.46627/sipose.v1i1.9.

[5] R. Rasmitadila et al., "The Perceptions of Primary School Teachers of Online Learning during the COVID-19 Pandemic Period: A Case Study in Indonesia," J. Ethn. Cult. Stud., vol. 7, no. 2, p. 90, 2020, doi: $10.29333 /$ ejecs/388.

[6] P. Sahu, "Closure of Universities Due to Coronavirus Disease 2019 (COVID-19): Impact on Education and Mental Health of Students and Academic Staff," Cureus, vol. 2019, no. 4, pp. 4-9, 2020, doi: 10.7759/cureus.7541.

[7] H. Pajarianto, A. Kadir, G. Nursaqinah, P. Sari, and S. Februanti, "Study from Home in the Middle of the COVID-19 Pandemic: Analysis of Religiosity, Teacher, and Parents Support Against Academic Stress," Talent Dev. Excell., vol. 12, no. 2, pp. 1791-1807, 2020.

D. Sibnath, E. Strodl, and J. Sun, "Academic Stress, Parental Pressure, Anxiety and Mental Health among Indian High School Students," Int. J. Psychol. Behav. Sci., vol. 5, no. 1, pp. 2634, 2015, doi: 10.5923/j.ijpbs.20150501.04.

[9] W. Cullen, G. Gulati, and B. D. Kelly, "Mental health in the Covid-19 pandemic," An Int. J. Med., vol. 113, no. 5, pp. 311-312, 2020.

[10] B. Choi, L. Jegatheeswaran, A. Minocha, M. Alhilani, M. Nakhoul, and E. Mutengesa, "The impact of the COVID-19 pandemic on final year medical students in the United Kingdom: a national survey," BMC Med. Educ., vol. 20, no. 1, p. 206, Dec. 2020, doi: 10.1186/s12909-02002117-1.

[11] C. H. Liu, S. Pinder-Amaker, H. "Chris" Hahm, and J. A. Chen, "Priorities for addressing the impact of the COVID-19 pandemic on college student mental health," J. Am. Coll. Heal., pp. 1-3, Oct. 2020, doi: 10.1080/07448481.2020.1803882.

[12] N. Hasan and Y. Bao, "Impact of 'e-Learning crack-up' perception on psychological distress among college students during COVID-19 pandemic: A mediating role of 'fear of academic 
year loss," Child. Youth Serv. Rev., vol. 118, p. 105355, 2020, doi: 10.1016/j.childyouth.2020.105355.

[13] R. Tennant et al., "The Warwick-Edinburgh mental well-being scale (WEMWBS): development and UK validation," Health Qual. Life Outcomes, vol. 5, no. 1, p. 63, 2007.

[14] B. Satici, M. Saricali, S. A. Satici, and M. D. Griffiths, "Intolerance of Uncertainty and Mental Wellbeing: Serial Mediation by Rumination and Fear of COVID-19," Int. J. Ment. Health Addict., pp. 1-12, 2020, doi: 10.1007/s11469-020-00305-0.

[15] W. Larcombe, C. Baik, and A. Brooker, "Teaching with student wellbeing in mind: A new initiative to support the mental health of university students," in New Idea \& Emerging Initiative]. Handbook and Proceedings of the Students, Transitions, Achievement, Retention \& Success (STARS) Conference, 2015, pp. 1-4, [Online]. Available: http://www.unistars.org/papers/STARS2015/02E .pdf.

[16] M. Z. Ahmed, O. Ahmed, Z. Aibao, S. Hanbin, L. Siyu, and A. Ahmad, "Epidemic of COVID19 in China and associated Psychological Problems," Asian J. Psychiatr, vol. 51, no. April, p. 102092, Jun. 2020, doi: 10.1016/j.ajp.2020.102092.

[17] M. Damaiyanti and D. Rahmah Fitriani, "The Relation of Educational Level, Academic Achievement (GPA) and Depression Among Public School Adolescent," Indones. J. Nurs. Pract., vol. 1, no. 3, 2017, doi: 10.18196/ijnp. 1365.

[18] S. C. K. Shaw, "Nurse Education in Practice Hopelessness, helplessness and resilience: The importance of safeguarding our trainees , mental," Nurse Educ. Pract., vol. 44, no. March, p. 102780, 2020, doi: 10.1016/j.nepr.2020.102780.

[19] T. Gillam and T. Gillam, "Creative Writing, Literature, Storytelling and Mental Health Practice," Creat. Wellbeing Ment. Heal. Pract., pp. 101-116, 2018, doi: 10.1007/978-3-31974884-9_7.

[20] R. L. Staricoff, "Arts in health: a review of the medical literature." Arts Council England London, 2004.

[21] S. Mcardle and R. Byrt, "Fiction, poetry and mental health: expressive and therapeutic uses of literature," J. Psychiatr. Ment. Health Nurs., vol. 8, no. 6, pp. 517-524, 2001.

[22] J. W. Pennebaker and J. D. Seagal, "Forming a story: The health benefits of narrative," J. Clin. Psychol., vol. 55, no. 10, pp. 1243-1254, 1999.
[23] R. J. Dolan, "Emotion, cognition, and behavior," Science (80-. )., vol. 298, no. 5596, pp. 11911194, 2002.

[24] M. Cabanac, "What is emotion?," Behav. Processes, vol. 60, no. 2, pp. 69-83, 2002.

[25] S. H. Kim and S. Hamann, "Neural correlates of positive and negative emotion regulation," $J$. Cogn. Neurosci., vol. 19, no. 5, pp. 776-798, 2007.

[26] E. Diener et al., "New well-being measures: Short scales to assess flourishing and positive and negative feelings," Soc. Indic. Res., vol. 97, no. 2, pp. 143-156, 2010.

[27] R. Becerra, D. Preece, G. Campitelli, and G. Scott-Pillow, "The assessment of emotional reactivity across negative and positive emotions: Development and validation of the Perth Emotional Reactivity Scale (PERS)," Assessment, vol. 26, no. 5, pp. 867-879, 2019.

[28] H. Maulana, N. Khawaja, and P. Obst, "Development and validation of the Indonesian Well-being Scale," Asian J. Soc. Psychol., vol. 22, no. 3, pp. 268-280, 2019, doi: 10.1111/ajsp.12366.

[29] L. M. Range and S. R. Jenkins, "Who Benefits from Pennebaker ' $\mathrm{s}$ Expressive Writing Paradigm? Research Recommendations from Three Gender Theories," vol. 08, pp. 149-164, 2010, doi: 10.1007/s11199-010-9749-7.

[30] J. M. Twenge, "The Multifactorial Approach and the Organization," vol. 23.

[31] Y. J. Wong, K. A. Pituch, and A. B. Rochlen, "Men ' S Restrictive Emotionality: An Investigation of Associations With Other Emotion-Related Constructs , Anxiety, and Underlying Dimensions," no. May 2014, 2006, doi: 10.1037/1524-9220.7.2.113.

[32] R. F. Bornstein, "Gender Schemas , Gender Roles , and Expressive Writing: Toward a Process-focused Model,” pp. 173-177, 2010, doi: 10.1007/s11199-010-9752-z.

[33] Z. Yang, X. Tang, W. Duan, and Y. Zhang, "and psychological health among Chinese undergraduates," no. 13, 2014, doi: 10.1002/ijop. 12081.

[34] T. Rose et al., "Measuring Mental Wellbeing Among Adolescents: A Systematic Review of Instruments," J. Child Fam. Stud., pp. 23492362, 2017, doi: 10.1007/s 10826-017-0754-0.

[35] S. Dhawan, "Online Learning: A Panacea in the Time of COVID-19 Crisis," J. Educ. Technol. Syst., vol. 49, no. 1, pp. 5-22, 2020, doi: $10.1177 / 0047239520934018$.

[36] D. Sikirit, "Learning from home during the COVID-19 pandemic," UNICEF Indonesia, 2020. 
https://www.unicef.org/indonesia/coronavirus/st ories/learning-home-during-covid-19-pandemic.

[37] D. E. Davis et al., "Thankful for the Little Things: A Meta-Analysis of Gratitude Interventions," vol. 63, no. 1, pp. 20-31, 2016.

[38] A. M. Wood, J. Maltby, R. Gillett, P. A. Linley, and S. Joseph, "The role of gratitude in the development of social support, stress, and depression: Two longitudinal studies," vol. 42, pp. $\quad 854-871, \quad 2008, \quad$ doi: 10.1016/j.jrp.2007.11.003.

[39] K. Goodall, "Individual differences in the regulation of positive emotion: The role of attachment and self esteem," Pers. Individ. Dif., vol. 74, pp. 208-213, 2015, doi: 10.1016/j.paid.2014.10.033. 